\title{
Opportunities and Challenges for the Inclusion of Soil-improving Crops in Vegetable Production Systems
}

\author{
Marianne Sarrantonio \\ Rodale Institute Research Center, Kutztown, PA 19530
}

The ability of certain crops to improve soil fertility or physical conditions has long been recognized. As early as the Chow dynasty (1134-247 B.C.) in China, there were reports of crops whose value for soil improvement was "greater than silkworm excrement" (Pieters, 1927). Romans around the time of Christ likewise waxed eloquently on the value of green manures, as in this line from Virgil: "Sow your wheat on land where grew the bean, the slender vetch or the fragile stalks of the bitter lupine."

The potential benefits of soil-improving crops (SIC-s) are many and varied. In addition to the continued use of legumes as a source of biologically fixed N, in more recent years, SICs have been commonly included in cropping systems to retard soil erosion and build up organic matter. In addition to these objectives, a 1988 survey of New England farmers using cover crops revealed that nearly half expected to derive some weed control from the SIC (Schonbeck, 1988). Fewer used SIC to conserve nutrients or make certain elements (such as P) more available, or to control insects and pests. Growers with soil compaction problems may grow a deeprooted SIC to break up dense soil layers (Foulds, 1989).

No single SIC can impart all the above benefits to a particular cropping system. In addition, there are some potential negative effects of SICs, including: depletion of soil moisture, lowering of spring soil temperatures, disruption of field operations, allelopathy, and the creation of habitat for harmful organisms. Even nitrate pollution of groundwater is a potential problem with the improper management of legumes in cropping systems. The realized value of the SIC to a particular cropping system will, of course, depend on the selection of species, management of those species, and interaction with the rest of the cropping system, including crops, weather, weed and pest pressures, and other components.

\section{SOIL-IMPROVING CROPS IN VEGETABLE SYSTEMS}

\section{Constraints}

Agronomic literature in the past 10 years has become weighty with research on the use of SICs in field crop rotations (Blevins et al., 1990; King, 1988; Ott and Hargrove, 1989; Power, 1987; Sarrantonio and Scott, 1988; Smith et al., 1987). The recognition of problems developing from such "rotations" as corn (Zea mays L.) alternating with bare ground, combined with annual cropping of hillsides has prompted much of this research. The fact that vegetable crops are more commonly grown on bottomland less subject to erosion and that rotations of vegetables tend to be more varied has made the need for SICs in vegetable systems appear less critical than in field cropping systems. The development of SIC/vegetable systems suffers additionally from the following constraints:

Complex rotations. Vegetable cropping, especially for the fresh market, may involve a single grower managing as many as a dozen crops per year. The vegetable grower's rotations tend to be more complicated than those of the field-crop grower. Timing of field operations, harvest, and marketing make it difficult to plan extra crops into the system, which may require additional labor, inputs, or management expertise. The diverse vegetable grower may have few low-labor periods during the growing season.

Intensive management. Vegetable land is often more intensively managed than field-crop land. High value crops tend to warrant more tender loving care, not to mention that they are more temperamental. Because of this, traffic in the field is heavier and may occur for longer 
periods of the crop growth. Certain hand-picked crops may require four or five harvesting trips through the field. This constant traffic puts physical limits on the establishment of cover crops while the commodity crop is in the field.

Need for flexibility. Many vegetable growers are reluctant to state a fixed rotation for their production fields; because of the larger number of choices available to them, they enjoy a certain amount of flexibility in their rotations that field-crop growers do not have. Even when the proportion of seasonal crops is predetermined, vegetable growers may not make decisions about the specific fields where crops will be grown until shortly before planting. This limits growers' ability to plan SICs into their rotations in the most efficient way.

Diverse crop needs. Crops grown in the same field during any given rotation may have drastically different needs. Crops for which the primary concern may be sufficiency of $\mathrm{N}$ may be followed closely by crops for which weed control is the essential element for good yields. Systems including SICs that account for the needs of the entire rotation, rather than one crop at a time, are that much more difficult to develop.

Use of blackplastic, mulches, and row covers. Vegetable crop production often includes the use of certain materials that will act as physical barriers to the establishment of SICs. Black plastic can act as a barrier while it is in the field and a source of stress when it is pulled up.

\section{Opportunities}

In spite of these constraints, growers and researchers have developed some novel approaches to including SICs in vegetable systems. Vegetable systems also offer certain opportunities that are not present in either orchard or field crop systems. Some of these are:

Complex rotations. Although this was mentioned above as a potential constraint, the wide diversity of crops on the farm may leave unexpected windows of opportunity, even for short periods, in the cropping system.

Flexibility. Vegetable growers have more opportunities to change their rotation plans in response to either good or bad results from the establishment of SICs. For example, if a SIC looks very vigorous in the spring, a grower may choose to wait and plant a summer annual in that field and establish the spring crop in another field.

Short croppingperiods. Many vegetable crops, such as lettuce (Lactuca sativa L.), remain in the field for a relatively short period, thus allowing for more multiple cropping. This situation also often leaves gaps in the growing season that might be filled by SICs.

Higher-value crops. Vegetable crops tend to be of higher value per unit area than field crops, so the relative cost of establishing a SIC will be lower. Also, their high value warrants the extra care that is sometimes required to properly establish a SIC.

Increased hand labor. Most fresh-market vegetable farms rely more on hand labor for crop production and harvesting than do fieldcrop farms. This need allows an opportunity for such operations as hand-spinning legume seed into standing vegetable crops, or perhaps hand-weeding to allow better establishment of the SIC.

Relatively smallfields. The patchwork nature of many small- to medium-sized market vegetable farms, with many small fields, affords two opportunities to use SICs: financial outlays for any given field will be small, and fields can be treated individually, according to their particular fertility or physical needs.

\section{TEMPORAL NICHES IN VEGETABLE CROPPING SYSTEMS}

There is an almost infinite number of combinations of vegetable crops that could make up a rotation for a given field, leaving open periods of anywhere from 1 day to a full year or more. Rather than focusing on the details of a specific rotation, I will deal with a few of the more common types of rotations that are seen on market vegetable farms in temperate, humid regions, and discuss some of the potential opportunities for the inclusion of SICs in these systems.

\section{Summer fallow}

A fairly common rotation in the northeastern United States involves sowing or transplanting a cool-season crop in the spring, which is harvested in late spring or early summer, followed by a summer fallow period of anywhere from 2 to 8 weeks, after which a fall crop is transplanted or sown. An example of this would be spring broccoli (Brassica oleracea Italica group) planted in mid- to late-April and harvested in mid-June, then a fallow period lasting -7 weeks, after which a fall lettuce crop is sown. There are at least three schemes for including a SIC into the summer fallow period (Fig. 1):

1) A SIC could be sown immediately following the completion of broccoli harvest. This would allow for any cleanup or residue removal or incorporation that would typically follow the broccoli harvest. The SIC could then be turned in before the sowing of the lettuce crop. This sequence would provide a growing period for the SIC of perhaps 5 weeks. The SIC would need to be one that broke down sufficiently quickly to create a smooth seedbed for the lettuce. Another option would be to kill the SIC by mowing or other means and leave it on the soil surface as a mulch into which the lettuce could be sown.

2) A SIC could be overseeded into the broccoli at some point after the broccoli was well established. This could significantly lengthen the growing period for the SIC. One obvious disadvantage is that the SIC would need to withstand considerable foot traffic during broccoli harvest. Also, broccoli residue removal would be more difficult. Incorporation of broccoli residue could not take place until the SIC was turned under. Timing of overseeding is crucial in this scheme. It is important to establish the SIC early enough for it to survive the shading by the broccoli canopy, but not so early that it begins to compete with the broccoli at head formation. Sowing the SIC immediately following or at the same time as final cultivation appears to be a viable option.

3) A SIC could be established after broccoli harvest as in 1) above, but rather than turning the residue under or killing it and leaving it on the surface, narrow strips could be tilled out of the SIC and the lettuce planted in the strips. The vigor of the SIC will probably need to be checked in some way to avoid competition with the young lettuce plants. This goal could most easily be achieved by mowing or perhaps lightly disking the SIC before lettuce planting. A variation of this system could of course include both overseeding of the broccoli and strip tillage for lettuce establishment; this would allow a maximum growing period for the SIC spanning the summer fallow period.

Species selection will vary somewhat, according to which of the above management schemes are chosen. Presuming that the primary purpose of the SIC is to provide $\mathrm{N}$ to the fall crop, species chosen to fit these niches should be warm-season legumes. In management scheme 1), with only 5 weeks in which to accumulate significant biomass and $\mathrm{N}$, the species will need to be one that germinates and grows extremely quickly under hot and possibly dry conditions.

\section{Warm Season Fallow EXAMPLE}

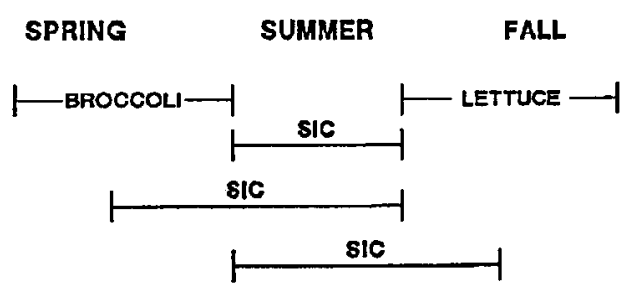

Fig. 1. Temporal niches that exist for soil-improving crops (SIC) in an example vegetable cropping system that includes a spring and fall crop. 
Several of the large-seeded tropical annual legumes have demonstrated the potential to fit this niche in Pennsylvania, provided there is sufficient moisture for germination. These species include cowpeas [Vigna unguiculata (L.) Walp.] lablab (Dolichos lablab L.), velvetbean [Mucuna deeringiana (Bort) Merr. and M. pruriens (L.) DC.] and several of the Canavalia spp. Crotalaria spp. have also shown rapid biomass accumulation during short summer growing periods in screening trials at the Rodale Inst. Research Center in southeastern Pennsylvania.

In management scheme 2), although rapid establishment is still desirable, some of the species above may actually establish too rapidly and begin to compete with the broccoli. Additionally, the vining habit of lablab and velvetbean may hamper harvesting operations. Demonstration trials at Rodale and on cooperating farmers' fields have shown that, for this area, 'Hubam' annual sweetclover (Melilotus alba Medik. var. annua) appears to have good potential as a summer overseeding. It established well under broccoli 2 years of the trial and grew rapidly when broccoli was harvested. Other species that appear to have some promise in this niche are cowpeas and Dolichos biflorus (L.), a relative of lablab.

Management scheme 3) would also most likely work best with nonvining species. A relatively low-statured clover that withstands mowing might be appropriate, or tropical forages such as Stylosanthes spp., siratro [Macroptilium atropurpureum (DC.) Urb.], or Lespedeza spp.

\section{Cool-season fallow: Example 1}

Rotations including summer annual vegetable crops often leave inadequate time for spring or fall vegetables in the cooler temperate regions, thus providing a temporal niche similar to that in corn or soybean [Glycine max (L.) Merr.] production systems: the coolseason (i.e., winter) fallow. This period may last as long as 9 months, but it also includes most of the least-hospitable months for crop growth in northern climates. An example might be fresh-market tomatoes (Lycopersicon esculentum Mill.) followed by tomatoes again the following year, or perhaps sweet corn. Although the weather provides some constraints, this system also offers more opportunities for the inclusion of SICs (Fig. 2), as described below:

1) A SIC could be sown, either drilled or broadcast, immediately following final harvest of the summer annual. In the case of tomatoes, this will limit the species selection greatly, as the harvest season may last up to the first frost; many winter annuals will not establish well that late in the fall. The SIC is then allowed to grow through the remainder of the fall, and may overwinter and continue growth in the spring until the field is prepared for the next summer annual crop.

\section{Cool Season Fallow}

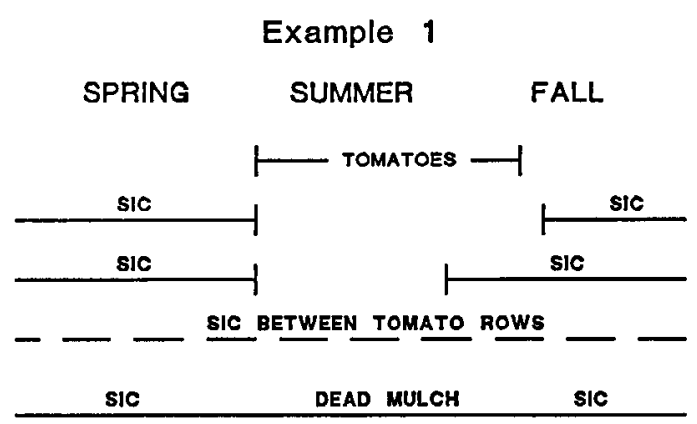

Fig. 2. Temporal niches that exist for soil-improving crops (SIC) in a vegetable cropping system with one annual summer crop per year.
The winter annuals could be plowed under the following spring or killed by mowing, in which case the next summer crop could be notill planted into the mulch. Several researchers and growers are working with similar systems. J. Luna at Virginia Polytechnic Inst. (personal communication) has had good success with tomatoes transplanted into a cut mulch of hairy vetch (Vicia villosa Roth.) and cereal rye (Secale cereale L.). The system was developed primarily for home gardeners but may have some application on a commercial scale.

2) The SIC could be overseeded into the summer annual crop at some point in the summer or early fall. The timing of the overseeding, as well as the species selection, would be determined largely by the primary purpose of the SIC. A crop that was included for soil conservation purposes or to protect the alleyways from compaction due to foot trafficwould best be sown soon after tomato transplanting. In this case, a warm-season grass might be the most appropriate choice. One tomato grower who is cooperating with us at Rodale sows annual ryegrass (Lolium multiflorum L.) immediately after tomatoes are transplanted as a protection against compaction as well as a means of weed control. He keeps the ryegrass mowed throughout the season.

If the primary purpose of the SIC is to furnish $\mathrm{N}$ to the annual crop the following summer, a late-summer overseeding would perhaps make more sense. This would allow the grower to use winter annual legumes, such as hairy vetch. These winter annuals do not perform well in the heat of the summer, and if seeded too soon, would likely initiate flowering before winter, leading to winter kill.

A multipurpose SIC that might provide soil protection, weed control, and $\mathrm{N}$ might include a mixture of perennial legumes such as white, red, or alsike clover (Trifolium repens L., T. pratense L., $T$. hybridum L.) and perennial turfgrasses. Such a mixture could be overseeded into the tomatoes after the final cultivation. In this case, the SIC would need to be either plowed under or killed with herbicides before the next summer annual is planted the following year.

3) Summer annual crops with relatively wide row spacings may lend themselves to living mulch or perennial cover crop systems. In this type of system, a perennial legume, grass, or mixture is established at some point in year 1 . In the early summer of year 2, strips are removed from the perennial sod with a rototiller or other implement, such as a chisel plow. Depending on the vigor of the cover, the SIC is suppressed by mowing, disking, or light rototilling, or perhaps with herbicides (tillage or herbicide application should not kill the sod, only suppress it until the summer annual is well established). Water is the most likely limiting factor in these systems, and irrigation greatly increases their chances of success. Peters (1986), V. Grubinger (personal communication), and others at Cornell Univ. have worked on such systems using white clover as a $\mathrm{N}$ source for sweet corn. Others have looked at similar living mulch management in sweet corn primarily for weed control (DeGregorio and Ashley, 1985).

4) A corollary to the above system creatively uses subterranean clover ( $T$. subterraneum L.) as a living/dead mulch for summer annual crops. The subclover is a winter annual that is established in the fall; it dies back naturally in late spring, leaving a weedsuppressing mulch that begins to release $\mathrm{N}$ almost immediately. A late-spring or summer vegetable crop can be no-till planted or transplanted into the mulch as it dies out, with little danger of competition. The subclover buries its seed pods in the ground as it dies, effectively planting them $\approx 1 \mathrm{~cm}$ into the soil. The seeds sprout in late summer, reestablishing the cover crop as the summer annual vegetable approaches harvest. These systems are being studied at Univ. of California, Davis, by Lanini et al., who are working primarily with lettuce and sweet corn (1989) and at Rutgers Univ. by R. Ilnicke (personal communication), who has had success with tomatoes, cole crops, and summer squash (Cucurbita spp.) in addition to sweet corn. Constraints to this system for temperate climates is the limited overwintering ability of the subclover. 


\section{Cool-season fallow: Example 2}

A more intensive rotation with summer annuals might include a short-season spring crop such as lettuce or spinach. The presence of the spring crop limits some of the options that existed in the example above. The temporal niches that exist in this system are illustrated in Fig. 3 and described below:

I) A SIC could be either sown after the summer annual crop or overseeded into it, as in management schemes 1) and 2) above. The constraint now is in the spring, when the growing period for the SIC has been considerably reduced by the presence of the spring vegetable. In such a case, one would need to find a winter annual with very vigorous growth in the fall, which would balance the shortened spring growing season. Certainly, establishing the SIC as early as possible the previous season would be an advantage. The winter annual in this case would still be in avegetative state when the spring vegetable is planted, and, therefore, would need to be killed by some means other than mowing. The spring crop might be delayed somewhat to allow more growth on the SIC, if this does not delay planting the summer annual. Such a management scheme would have greater chance of success in areas with a long growing season, such as in North Carolina, where North Carolina State Univ. researchers have no-till planted potatoes and broccoli into springkilled winter covers (Hoyt, 1984).

2) In the situation above, a SIC could be chosen for vigorous fall growth that is known to winter-kill. This would provide a dead mulch into which the spring crop could be no-till planted. In Pennsylvania, two species that fit this niche are oats (Avena sativa L.) and woolypod vetch (Vicia villosa Roth. subsp. dasycarpa). Woolypod vetch grows

\section{Cool Season Fallow}

\section{Example 2}

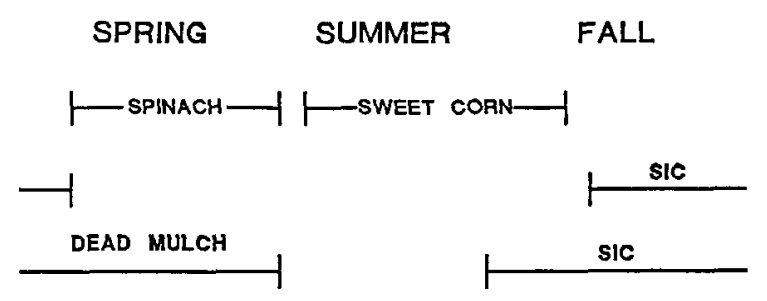

- SIC BETWEEN VEGETABLE ROWS

Fig. 3. Temporal niches that exist for soil-improving crops (SIC) in a vegetable cropping system that includes both a spring and summer crop.

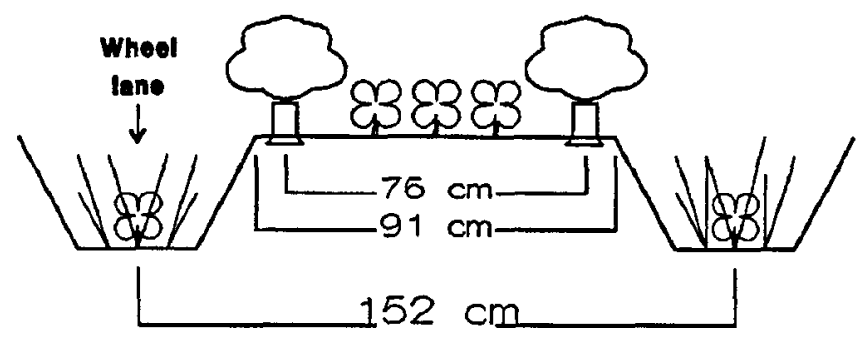

Fig. 4. Some spatial niches that exist for soil-improving crops (SIC) in an example of a permanent bed system. Diagram shows two crop rows on edges of the bed, with soil-improving crops between the crop rows on the bed, as well as in the wheel lane separating beds. much more rapidly than hairy vetch in cool weather in our climate, but has much less cold tolerance. In screening trials at Rodale, 'Lana' woolypod vetch planted in mid-August left a thick dead mulch the following spring that suppressed weeds until at least mid-May.

3) The spring crop could be overseeded with a SIC, either a warmseason annual or perennial mixture. The summer annual vegetable could then be strip-tilled into this cover. This system has some obvious constraints: it will be difficult, though not impossible, to manage the timing of field operations to allow a cover to establish, harvest crop 1, and plant crop 2 without overly disrupting the SIC.

\section{SPATIAL NICHES IN VEGETABLE CROPPING SYSTEMS}

\section{Permanent beds}

The use of permanent beds is a means of restricting the field traffic to narrow bands between cropped areas. The width of the beds, which may or may not be raised, is then roughly equal to the width between tractor wheels. As might be expected, the wheel lanes are vulnerable to becoming highly compacted. The establishment of SICs in this lane could help alleviate part of the compaction problem (Fig. 4), as well as provide traction during wet periods.

The SIC would be most logically and primarily a sod-forming perennial grass, although it might include a low-growing annual legume such as white clover. The beds themselves would be managed as any other vegetable system, and SICs could be included as overseedings, living mulches, or short-season fallow crops as described in the temporal niches above. Finally, SICs could be grown in a certain proportion of the beds, perhaps one in three, while vegetables are grown in the other two (Fig. 5). Vegetable crops could be rotated to these beds to benefit from the SIC, or the biomass from the SIC could be applied to an adjacent bed, perhaps by using a mower that could blow the cuttings several feet to the side. A permanent bed system based on 152 -cm beds, being developed by T. Schettini at Rodale, incorporates all three niches for SICs.

\section{Field borders}

Field borders can sometimes be used to grow SICs, which can then be cut and applied as mulch to adjacent vegetable crops. The SIC would need to be one that produces copious biomass, considering the reduced space it is allowed, and one that responds well to cutting. This management scheme would have its greatest applicability in home gardens, or very small fields.

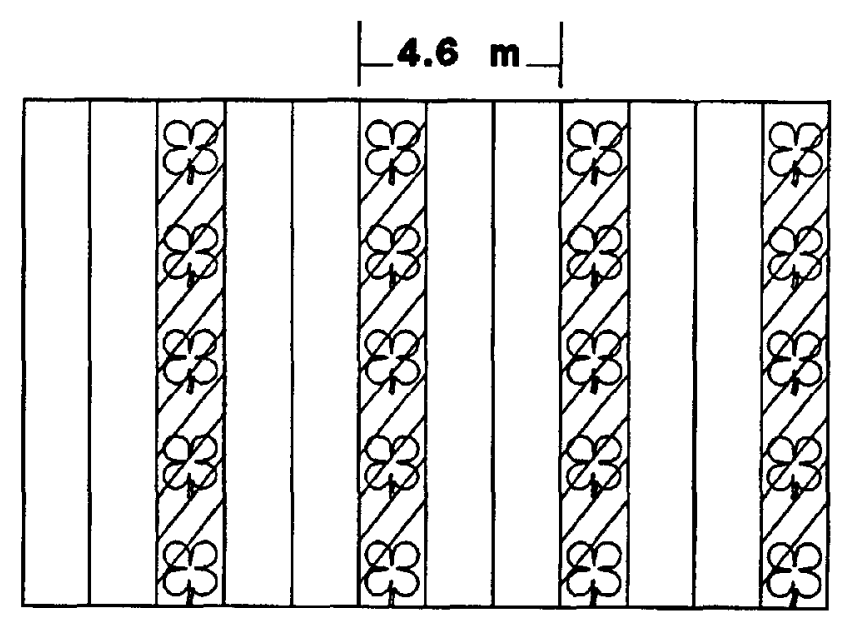

Fig. 5. Schematic of permanent bed system with every third bed dedicated to soil-improving crops. 


\section{Alternating strip (mow/blow)}

A system similar to the alternating bed system described above could easily be established without permanent beds. Vegetable crops are alternated in strips with green manure crops. As above, the vegetable is then rotated onto the green manure strip, or the green manure biomass is applied to the vegetable crop by mowing and blowing.

\section{OTHER OPPORTUNITIES FOR INCLUDING SICS}

\section{Full-season fallow}

Vegetable farmers with sufficient land may be able to leave some of their fields fallow for as much as a year, allowing them to establish a full-year SIC to build up organic matter or provide $\mathrm{N}$ to succeeding crops.

\section{Alley cropping}

Alley cropping has been promoted as an appropriate cropping technology for sloping land, primarily in the tropics. Trees or shrubs, usually leguminous, are planted in rows separated by 2- to 6-m alleyways in which the crop plants are grown. The trees or shrubs are pruned periodically and the prunings are applied to the cropped area. This system may have some application for vegetable production on hillsides in temperate areas. R. Janke at the Rodale Inst. is currently screening leguminous trees for their potential in such a system in Pennsylvania.

\section{Composting}

Soil-improving crops can be grown at any site on the farm, then cut and removed to make compost. Fresh legume leaves are an excellent source of $\mathrm{N}$ to mix with compost material that is highly carbonaceous, such as straw or leaves. Although labor-intensive, composting a SIC may extend its ability to increase soil organic matter in localized places on the farm.

\section{THE IDEAL SOIL-IMPROVING CROP}

All the above plans involve a careful meshing of species selection and management techniques. Results are likely to be best when growers have a clear idea of their primary objectives in using a SIC and are willing to invest the extra time to make the system work. Such a system will approximate the ideal if the SIC: Occupies underused time or space in the existing system; is well matched to the cropping system needs; does not compete with the vegetable crop for light, water, or nutrients; attracts beneficial organisms; does not harbor pests; is easy and inexpensive to establish; tolerates field traffic well; and requires little or no extra tillage.

There are many other examples of innovative uses of SICs that are not discussed here. Growers have been particularly creative in this area; organic and low-input producers have a deep appreciation for the need to improve soil structure, fertility, and biological activity. Soil-improving crops will continue to play a crucial role in achieving highly productive and sustainable soil and vegetable systems.

\section{Literature Cited}

Blevins, R.L., J.H. Herbek, and W.W. Frye. 1990. Legume cover crops as a nitrogen source for no-till corn and grain sorghum. Agron J. 82:769-773.

DeGregorio, R.E. and R.A. Ashley. 1985. Screening living mulches and-cover crops for weed suppression in no-till sweet corn. Proc. Northeast Weed Soc. 39:80-84.

Foulds, C. 1989. Interseedings in vegetable production. R.E.A.P. Nwsl. 2(4):6-8.

Hoyt, G.D. 1984. The effect of cover crops on strip-till vegetable and tobacco production. Soil Sci. Soc. North Carolina Proc. 27:1020.

Ring, L.D. 1988. Legumes for nitrogen and soil productivity. Stewardship News, Fall 1988:4-6.

Lanini, W.T., D.R. Pittinger, W.L. Graves, F. Munoz, and H.S. Agamalian. 1989. Subclovers as living mulches for managing weeds in vegetables. Calif. Agr. 43(6):25-27.

Ott, S.L. and W.L. Hargrove. 1989. Profits and risks of using crimson clover and hair vetch cover crops in no-till corn production. Amer. J. Alternative Agr. 4(2):65-70.

Peters. S.E. 1986. Nitrogen interactions in a sweet corn and white clover living mulch cropping system. MS Thesis, Cornell Univ., Ithaca, N.Y.

Pieters, A.J. 1927. Green manuring. Wiley, New York.

Powers, J.F. (ed.). 1987. The role of legumes in conservation tillage systems. Soil Conserv. Soc. Amer., Ankeny, Iowa.

Sarrantonio, M. and T.W. Scott. 1988. Tillage effects on the availability of nitrogen to corn following a winter green manure crop. Agron. J. 52:1661-1668.

Smith, M.S., W.W. Frye, and J.J. Varco. 1987. Legume wintercover crops. Adv. Soil Sci. 7:95-139. 